\title{
Effects of dexmedetomidine on heart arrhythmia prevention in off-pump coronary artery bypass surgery: A randomized clinical trial
}

\author{
Ghasem Soltani ${ }^{1}$, Saeed Jahanbakhsh ${ }^{1}$, Mohammad Abbasi Tashnizi², Mehdi Fathi ${ }^{1}$, Shahram Amini' ${ }^{1}$, Nahid \\ Zirak $^{1}$, Shima Sheybani ${ }^{3}$
}

\begin{abstract}
${ }^{1}$ M.D, Anesthesiologist, Associate Professor, Department of Anesthesiology, Faculty of Medicine, Mashhad University of Medical Sciences, Mashhad, Iran

${ }^{2}$ M.D, Cardiac Surgeon, Associate Professor, Department of Cardiac Surgery, Faculty of Medicine, Mashhad University of Medical Sciences, Mashhad, Iran

${ }^{3}$ M.D, Anesthesiologist, Fellowship of Cardiac Anesthesiology, Assistant Professor, Department of Anesthesiology, Faculty of Medicine, Mashhad University of Medical Sciences, Mashhad, Iran
\end{abstract}

\section{Type of article: Original}

\begin{abstract}
Background: Arrhythmia occurring during and after surgery is one of the major complications in open-heart surgery. Dexmedetomidine is an intravenous alpha-2 agonist and very specific short-acting drug to protect the various organs against ischemic injuries and blood reflow. However, the effect of dexmedetomidine for preventing intraoperative heart arrhythmias has not been recognized.

Objective: This study aimed to determine the effect of dexmedetomidine on the incidence rate of heart arrhythmias and anesthetic required in off-pump coronary artery bypass surgery.

Methods: This randomized clinical trial was conducted on patients who were candidates for off-pump coronary artery bypass referring to Imam Reza Hospital of Mashhad, Iran, from July 2016 through January 2017. The patients were randomly assigned to two groups of intervention (infusion of $0.5 \mathrm{mcg} / \mathrm{kg} / \mathrm{h}$ dexmedetomidine together with induction followed by infusion of $0.5 \mathrm{mcg} / \mathrm{kg} / \mathrm{h}$ by the end of the surgery) or control (saline infusion). Mean arterial pressure (MAP) and heart rate (HR) were measured before induction, during surgery operation and ICU admission. Data were analyzed by SPSS version 18 using Chi Square and independentsamples t-test.
\end{abstract}

Results: A total of 76 patients with a mean age of $59.8 \pm 8.2$ years (in two groups of 38 ) were studied. The two groups had no statistically significant difference in terms of background variables. The MAP and HR values before induction, during surgery and ICU admission were significantly higher in the control group than in the intervention group $(\mathrm{p}=0.001)$. Out of the studied arrhythmias, the values of PAC $(55.2 \%$ vs. $15.7 \%)$, PVC $(81.5 \%$ vs. $21.0 \%)$, AF (26.3\% vs. $7.8 \%)$, VTAC $(21.0 \%$ vs. $2.6 \%)$ were significantly lower in dexmedetomidine group $(\mathrm{p}=0.001)$.

Conclusion: It seems that dexmedetomidine administration during induction and surgery can cause significant reduction in most of the common arrhythmias in off-pump coronary bypass surgery. The use of dexmedetomidine maintains MAP and HR at significantly lower values, and changes compared to the control group as well as reduces the need for anesthetic compounds.

Trial Registration: The present study has been registered at the Iranian Registry of Clinical Trials (www.IRCT.IR) with a code of IRCT2016072413159N9 before starting the study.

Founding: This study was fully sponsored by the Research Deputy at Mashhad University of Medical Sciences, Iran (grant number 941413).

Keywords: Coronary Bypass, Dexmedetomidine, Mean Arterial Pressure, Heart rate, Arrhythmia

\section{Corresponding author:}

Assistant Professor Dr. Shima Sheybani, Faculty of Medicine, Mashhad University of Medical Sciences, Mashhad, Iran. Tel: +98.5137647230, Email: sheybanish@mums.ac.ir

Received: May 15, 2017, Accepted: August 10, 2017, Published: October 2017

iThenticate screening: August 02, 2017, English editing: September 21, 2017, Quality control: October 02, 2017

This article has been reviewed / commented by three experts

(C) 2017 The Authors. This is an open access article under the terms of the Creative Commons Attribution-NonCommercialNoDerivs License, which permits use and distribution in any medium, provided the original work is properly cited, the use is non-commercial and no modifications or adaptations are made. 


\section{Introduction}

In recent years, the consequences of cardiac surgery have been remarkably improved by means of advances in techniques for anesthesia, cardiac surgery, postoperative care and use of the cardiopulmonary bypass (1). However, the incidence rate of cardiac arrhythmia (15-50\%) is still one of the common complications following coronary artery bypass graft $(1,2)$. In addition, intraoperative hemodynamic disorders, caused by changes in plasma levels of epinephrine and norepinephrine after surgical stimulation, are some of the challenges for patients undergoing CABG surgery (3). Hemodynamic disruption causes imbalance in myocardial oxygen supply and demand, and eventually leads to myocardial ischemia, resulting in increased incidence of cardiovascular events and mortality (3). Studies have also indicated that the incidence of arrhythmias during surgery is associated with increased healthcare costs and prolonged hospitalization and higher mortality $(1,4,5)$. Although many preventive strategies have been proposed to impede heart arrhythmias and hemodynamic disorders during CABG, there are still no novel suggested compounds that could strictly and routinely be used in the health care system. Dexmedetomidine is a very specific intravenously and short-acting alpha-2 agonist which theoretically reduces the sympathetic output by decreasing serum levels of norepinephrine, and results in reduction of the incidence of tachycardia, inflammation, high blood pressure, delirium, anxiety and the need for analgesics during and after surgery $(6,7)$. Numerous clinical trials have still not accurately determined whether the use of dexmedetomidine could prevent the occurrence of common heart arrhythmias during CABG or not (1, 8-11). A recently published meta-analysis reported the dexmedetomidine as an effective compound for controlling atrial fibrillation, but its use, based on observations, is associated with hypotension (1). However, in the same study, conducting further studies was suggested due to the low number of clinical trials conducted on the effect of dexmedetomidine on the clinical outcome for CABG surgery. Therefore, this study aimed to determine the effect of intraoperative administration of dexmedetomidine on incidence rate of cardiac arrhythmia and hemodynamic monitoring, as well as the need for anesthetic and analgesic requirements during off-pump cardiopulmonary bypass surgery.

\section{Material and Methods}

\subsection{Study design and setting}

This randomized and blinded clinical trial was conducted on patients undergoing CABG referred to the cardiac surgery ward at Imam Reza Hospital of Mashhad in Iran from June 2016 to January 2017.

\subsection{Participants}

Inclusion criteria were the patients undergoing off-pump CABG surgery, ASA class II and III, age range of 30 to 85 years and ventricular ejection fraction (EF) of more than 35\%. Exclusion criteria included history of heart arrhythmias or block, history of previous cardiac surgery, valvular heart disease and large left atrium or cardiomegaly. The CONSORT diagram is illustrated in Figure 1.

\subsection{Sampling}

Sample size for each group was estimated at least 33 subjects (a total of 66 patients) using the equation for comparing two proportions and considering $\alpha=5 \%, \beta=20 \%, \mathrm{Z}_{1-\alpha / 2}=1.96, \mathrm{P}_{1}=80 \%$ and $\mathrm{P}_{2}=49 \%$. Simple random sampling method was used to select samples. Patients were allocated into two groups with a simple randomization method.

\subsection{Interventions}

The patients were randomly assigned to either the control or the intervention group using a sealed envelope. In both groups, anesthesia induction was performed by $0.5 \mathrm{mg} / \mathrm{Kg}$ of midazolam, $10 \mathrm{mcg} / \mathrm{kg}$ of Sufentanil, $0.5 \mathrm{mg} / \mathrm{kg}$ of atracurium and $1.5 \mathrm{mg} / \mathrm{kg}$ of propofol. The intervention group received $0.5 \mathrm{mcg} / \mathrm{kg} / \mathrm{h}$ of dexmedetomidine at the time of induction and then infusion of $0.5 \mathrm{mcg} / \mathrm{kg} / \mathrm{h}$ of dexmedetomidine by the end of the surgery and the transfer to the cardiac intensive care unit (CICU). Normal saline was used instead of dexmedetomidine in the control group with the same procedure. The cardiovascular control and Bispectral Index (to maintain BIS $=40-60$ ) were monitored in both of the groups. Anesthesia was maintained by $50 \mathrm{mcg} / \mathrm{kg} / \mathrm{min}$ of propofol, sufentanil and midazolam with regard to anesthetic depth (to maintain of BIS $=40-60$ ) and MAP controlling (to maintain of 90>MAP $>60 \mathrm{mmHg}$ ). If the MAP were decreased more than $30 \%$ during the surgery, initially liquid therapy then dexmedetomidine infusion would be reduced up to half, and the inotrope dobutamine or epinephrine would be infused. Upon the level of MAP being reached to the pre-reduction level, dexmedetomidine infusion was returned to baseline level. If the level of MAP were elevated more than $30 \%$, nitroglycerin infusion would be used; types and amounts of used drugs were recorded. 


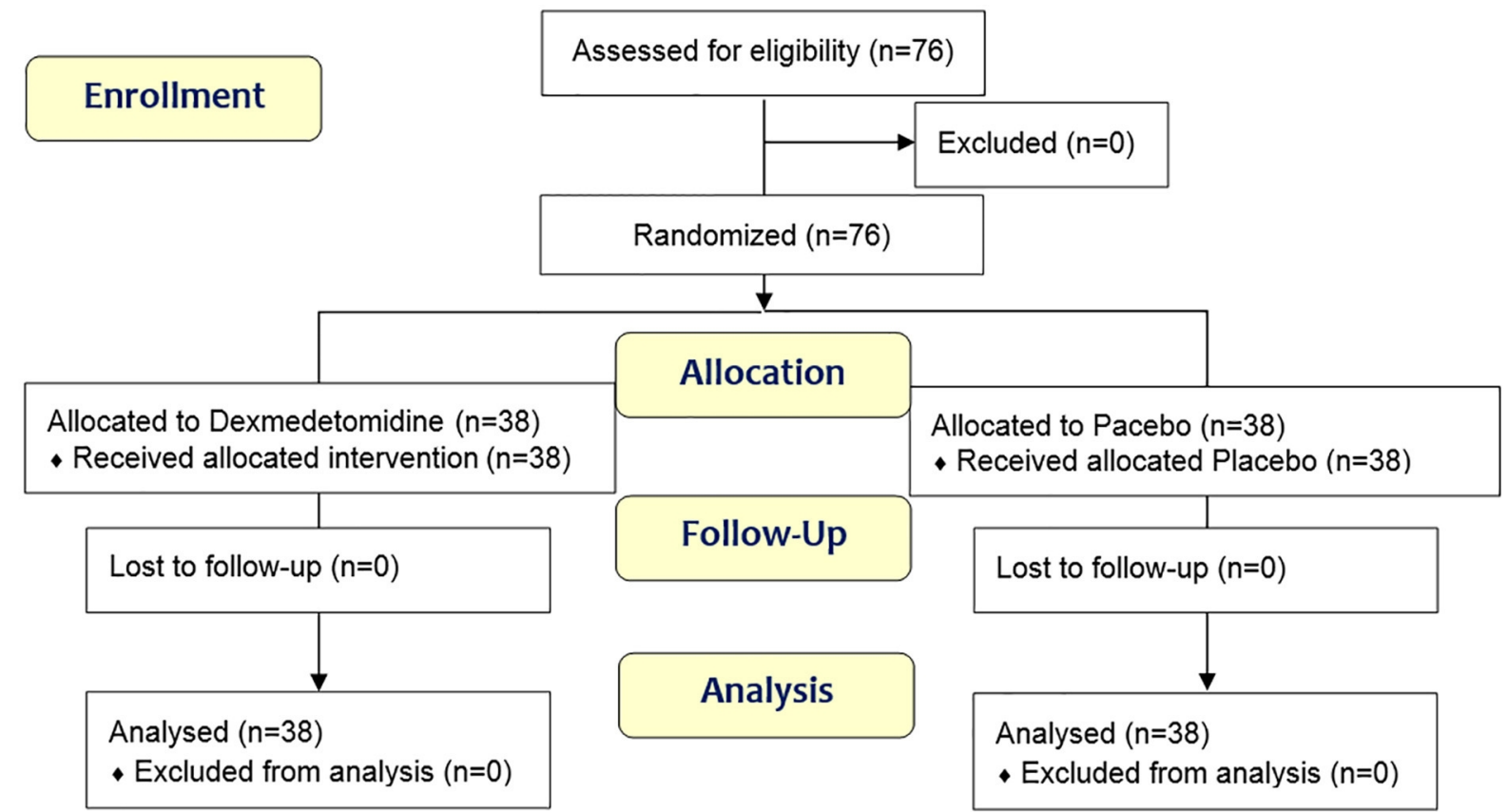

Figure 1. CONSORT diagram showing the flow of participants through each stage of a randomized trial

\subsection{Data Collection}

Information such as gender, age, weight, known cardiovascular risk factors and a history of chronic disease were noted for the patients before the surgery, using a checklist. Then the ventricular ejection fraction was reported using echocardiography performed by a cardiologist of the heart surgery ward (same person) and the levels of platelets, hemoglobin and INR recorded in preoperative tests was recorded for the patients in the checklist. General anesthesia was performed in accordance with the above-mentioned standard protocols; intervention type for each patient was acted by a cardiac anesthesia fellowship based on the sealed envelope. All patients underwent off-pump CABG surgery by an experienced associate professor of cardiovascular surgery. Data of the checklist were completed during the surgery by a cardiac anesthesia fellowship that was unaware of the other phases of the research.

\subsection{Hemodynamic changes and arrhythmia}

Mean arterial pressure (MAP) and heart rate (HR) were recorded before induction of anesthesia, during laryngoscopy and sternotomy, 30 minutes after induction, during handling of the distal grafts and proximal grafts, during sternal closure and ICU admission. The MAP and HR were measured using Saadat monitoring devices (Saadat CO., Iran) and maintain BIS between 40 and 60. Immediately after induction of anesthesia, the reduction in MAP over $30 \%$ was treated by $5 \mathrm{mg}$ of intravenous ephedrine and liquid therapy and the reduction in HR less than 50 was treated by $0.5 \mathrm{mg}$ of atropine; the medications used were recorded in the checklist of each patient. In addition, the incidence of arrhythmias such as bradycardia, asystole, PAC, PVC, AF, flutter, VTAC, first, second or third-degree blocks were recorded from the start of induction to ICU admission. Furthermore, taking status of medications including Esmolol, labetalol, propanol, lidocaine, amiodarone, TNG, Dobutamine, dopamine, epinephrine, norepinephrine, propofol, sufentanil and midazolam for the management of the hemodynamic or arrhythmic disorders as well as the use of synchronized and unsynchronized shocks or balloon pump were inserted in the checklist.

\subsection{Outcomes}

The first outcome was to compare the incidence rate of each type of cardiac arrhythmia between the two groups. The second assessed outcome was comparison of the MAP and HR between two groups. The third outcome was the number of anesthetic drugs and narcotics and inotropes used during surgery.

\subsection{Statistical analysis}

Data were reported as mean \pm standard deviation for continuous variables and also as statistics and percentages for categorical variables. In data analysis, initially the normality of the data was assessed by a one-sample Kolmogorov- 
Smirnov test modified by Lilliefors, and appropriate statistical test was determined. Repeated measures test was used to compare changing trends of hemodynamic parameters. Chi square test was applied to assess the frequency of arrhythmias between the two groups and independent-samples t-test to compare MAP, HR and the amount of need for drug between both groups. Data were analyzed using SPSS version 18 (SPSS Inc. Chicago, Illinois, USA).

\subsection{Ethics}

Each patient voluntary signed the informed consent form after full explanation on study design and objectives. This research project was approved by the Ethics Committee of Mashhad University of Medical Sciences, Iran (Research ethic code: IR.MUMS.fm.REC.1394.704). In case of incidence of any complication related to research, the patients were fully supported by the researchers. The present study has been registered at the Iranian Registry of Clinical Trials (www.IRCT.IR) with a code of IRCT2016072413159N9 before starting the study.

\section{Results}

\subsection{Baseline characteristics}

A total of 76 patients were enrolled in the study. There was no excluded patient; so the study was conducted on 76 patients with a mean age of $59.8 \pm 8.2$ years. In this study, 38 patients were allocated in the control group and 38 patients in dexmedetomidine group. There was no statistically significant difference between the two groups in terms of age, gender, weight, history of chronic disease and cardiovascular risk factors, echocardiographic left ventricular ejection fraction, as well as basic hematological tests together (Table 1).

\subsection{Operative findings}

In addition, there was no statistically significant difference between the two groups in terms of surgery duration and the number and type of grafts. Among the findings during surgery, as the average number of received packed cell units in the control group was significantly higher than the dexmedetomidine group; however, no difference was observed between the numbers of received unit in other blood products (Table 2).

\subsection{Mean arterial pressure and heart rate}

The MAP value in the patients of the control group was significantly greater than that of the dexmedetomidine group at all evaluated time points before induction, during sternotomy, 30 minutes after induction, during distal anastomosis, during closure of sternum and ICU admission, except for during proximal anastomosis (Table 3). The least recorded MAP in both control and dexmedetomidine groups was associated with proximal anastomosis time, respectively $59.2 \pm 6.0$ and $64.1 \pm 9.8 \mathrm{mmHg}$. The highest recorded MAP in the two groups was before induction (control $=116.8 \pm 16.0$ versus dexmedetomidine $=98.8 \pm 19.6$ ). The $H R$ in patients in the control group was statistically significantly higher than the dexmedetomidine group at all studied time points of before induction, during sternotomy, 30 minutes after induction, during distal and proximal anastomosis, during closure of sternum, and ICU addmition (Table 3). The minimum recorded HR was in the control group during distal anastomosis time $(84.0 \pm 9.6 \mathrm{bpm})$ and in the dexmedetomidine group at 30 minutes after induction $(65.5 \pm 11.3$ beats per min) (Table $3)$.

\subsection{Intraoperative arrhythmias}

The most commonly observed intraoperative arrhythmia was PVC (51.3\%), and then PAC, and AF had the highest incidence rates, 35.5\% and $17.1 \%$ respectively. Asystole, atrial flutter, first-degree block and third-degree block were not observed in any of the examined patients. The incidence rate of PAC, PVC, AF and VTAC arrhythmias in the dexmedetomidine group was significantly lower than in the control group (Table 4). In 13 patients of the control group versus 2 patients in the intervention group, the changes were observed in ST wave (in ascending or descending order). No cardiac arrest or myocardial infarction was observed in any of the patients between the two groups.

\subsection{Pharmaceutical and non-pharmaceutical interventions of antiarrhythmics and hemodynamic controller}

The results indicated that the dosage of propofol, sufentanil and midazolam in the control group was significantly higher compared to the intervention group. Also, administration of TNG, dobutamine, epinephrine, lidocaine and esmolol was significantly more used in the control group. There was no statistically significant difference between the two groups in terms of other antiarrhythmics treatment actions and hemodynamic controller (Table 5). 
http://www.ephysician.ir

Table 1. Comparison of background variables between the dexmedetomidine and control groups undergoing offpump coronary artery bypass surgery

\begin{tabular}{|l|l|l|l|}
\hline Variables & Control $(\mathrm{n}=38)$ & Dexmedetomidine $(\mathrm{n}=38)$ & $\mathrm{p}$-value \\
\hline Gender, male/female, $(\mathrm{n})$ & $18 / 20$ & $13 / 25$ & 0.200 \\
\hline Age (year), mean \pm SD & $59.4 \pm 9.3$ & $60.3 \pm 7.1$ & 0.640 \\
\hline Weight $(\mathrm{kg})$, mean $\pm \mathrm{SD}$ & $73.6 \pm 16.0$ & $72.1 \pm 10.9$ & 0.647 \\
\hline Diabetes, $\mathrm{n}(\%)$ & $18(47.3)$ & $13(34.2)$ & 0.243 \\
\hline Hyperlipidemia, $\mathrm{n}(\%)$ & $14(36.8)$ & $13(34.2)$ & 0.811 \\
\hline Hypertension, $\mathrm{n}(\%)$ & $27(71.0)$ & $25(65.7)$ & 0.622 \\
\hline Myocardial infarction, $\mathrm{n}(\%)$ & - & $1(2.6)$ & 0.314 \\
\hline Cardiac ischemia, $\mathrm{n}(\%)$ & $38(100)$ & $38(100)$ & - \\
\hline Asthma, $\mathrm{n}(\%)$ & $1(2.6)$ & - & 0.314 \\
\hline Chronic lung disease, $\mathrm{n}(\%)$ & - & - & - \\
\hline Chronic kidney disease, $\mathrm{n}(\%)$ & - & - & - \\
\hline Liver disease, $\mathrm{n}(\%)$ & - & - & - \\
\hline Thyroid disease, $\mathrm{n}(\%)$ & - & - & - \\
\hline Drug addiction, $\mathrm{n}(\%)$ & $4(10.5)$ & $6(15.7)$ & 0.496 \\
\hline Ventricular ejection fraction $(\%)$, mean $\pm \mathrm{SD}$ & $50.7 \pm 7.0$ & $52.2 \pm 7.2$ & 0.483 \\
\hline Platelet levels, $(\mu \mathrm{L} / 103)$, mean $\pm \mathrm{SD}$ & $230.5 \pm 55.5$ & $233.7 \pm 54.1$ & 0.798 \\
\hline INR (ratio), mean \pm SD & $1.03 \pm 0.1$ & $1.06 \pm 0.1$ & 0.382 \\
\hline Hemoglobin, $(\mathrm{g} / \mathrm{dL})$, mean $\pm \mathrm{SD}$ & $12.9 \pm 1.9$ & $13.3 \pm 1.4$ & 0.463 \\
\hline
\end{tabular}

Table 2. Comparison of results associated with off-pump coronary artery bypass surgery between the two dexmedetomidine and control groups

\begin{tabular}{|l|l|l|l|}
\hline Variables & Control $(\mathrm{n}=38)$ & Dexmedetomidine $(\mathrm{n}=38)$ & $\mathrm{p}$-value \\
\hline Graft number, $(\mathrm{n})$, mean $\pm \mathrm{SD}$ & $3.3 \pm 0.6$ & $3.1 \pm 0.8$ & 0.282 \\
\hline RCA graft, $\mathrm{n}(\%)$ & $27(71.0)$ & $22(57.8)$ & 0.231 \\
\hline Diagonal graft, $\mathrm{n}(\%)$ & $27(71.0)$ & $23(60.5)$ & 0.333 \\
\hline OM graft, $\mathrm{n}(\%)$ & $33(86.8)$ & $28(73.6)$ & 0.150 \\
\hline PDA graft, $\mathrm{n}(\%)$ & $1(2.6)$ & $3(7.8)$ & 0.304 \\
\hline LAD graft, $\mathrm{n}(\%)$ & $37(97.3)$ & $38(100)$ & 0.314 \\
\hline Ramos graft, $\mathrm{n}(\%)$ & $2(5.2)$ & $4(10.5)$ & 0.395 \\
\hline LM graft, $\mathrm{n}(\%)$ & $2(5.2)$ & $3(7.8)$ & 0.644 \\
\hline Intraoperative hemorrhage, $(\mathrm{cc})$, mean $\pm \mathrm{SD}$ & 1373.6541 .6 & $830.2 \pm 364.5$ & 0.000 \\
\hline Packed cell unit, $(\mathrm{n})$, mean \pm SD & $1.5 \pm 1.0$ & $0.84 \pm 0.7$ & 0.002 \\
\hline Platelet units, $(\mathrm{n})$ & - & - & - \\
\hline Units of FFP, $(\mathrm{n})$, mean \pm SD & $0.07 \pm 0.3$ & $0.02 \pm 0.1$ & 0.548 \\
\hline Duration of surgery, (hours), mean $\pm \mathrm{SD}$ & $5.1 \pm 1.0$ & $4.8 \pm 1.0$ & 0.119 \\
\hline
\end{tabular}

Table 3. Comparison of mean arterial pressure and heart rate between the dexmedetomidine and control groups undergoing off-pump coronary artery bypass surgery

\begin{tabular}{|c|c|c|c|c|}
\hline \multicolumn{2}{|l|}{ Variables, mean $\pm \mathrm{SD}$} & Control $(\mathrm{n}=38)$ & Dexmedetomidine $(\mathrm{n}=38)$ & p-value \\
\hline \multirow{7}{*}{$\begin{array}{l}\text { Mean arterial pressure, } \\
(\mathrm{mmHg})\end{array}$} & Before induction & $116.8 \pm 16.0$ & $98.8 \pm 19.6$ & 0.000 \\
\hline & During sternotomy & $100.8 \pm 10.5$ & $78.7 \pm 10.5$ & 0.000 \\
\hline & 30 minutes after induction & $84.8 \pm 7.4$ & $72.1 \pm 8.9$ & 0.000 \\
\hline & During distal anastomosis & $89.9 \pm 6.7$ & $68.1 \pm 11.2$ & 0.000 \\
\hline & During proximal anastomosis & $59.2 \pm 6.0$ & $64.1 \pm 9.8$ & 0.011 \\
\hline & During closure of the sternum & $79.5 \pm 4.9$ & $69.2 \pm 9.5$ & 0.000 \\
\hline & ICU admission & $83.1 \pm 5.3$ & $69.8 \pm 8.9$ & 0.000 \\
\hline \multirow{8}{*}{$\begin{array}{l}\text { Heart rate (number per } \\
\text { minutes) }\end{array}$} & Before induction & $94.8 \pm 11.8$ & $84.9 \pm 13.7$ & 0.000 \\
\hline & During laryngoscopy & $93.6 \pm 9.7$ & $72.6 \pm 13.0$ & 0.000 \\
\hline & During sternotomy & $91.2 \pm 9.3$ & $69.1 \pm 11.1$ & 0.000 \\
\hline & 30 minutes after induction & $80.6 \pm 10.2$ & $65.5 \pm 11.3$ & 0.000 \\
\hline & During distal anastomosis & $84.0 \pm 9.6$ & $70.3 \pm 11.0$ & 0.000 \\
\hline & During proximal anastomosis & $103.7 \pm 13.3$ & $70.2 \pm 13.2$ & 0.000 \\
\hline & During closure of sternum & $91.7 \pm 6.6$ & $67.3 \pm 12.1$ & 0.000 \\
\hline & ICU admission & $89.5 \pm 6.7$ & $66.7 \pm 11.3$ & 0.000 \\
\hline
\end{tabular}


Table 4. Comparison of absolute frequency of intraoperative arrhythmias between the dexmedetomidine and control groups undergoing off-pump coronary artery bypass surgery

\begin{tabular}{|l|l|l|l|}
\hline Variables, $\mathrm{n}(\%)$ & Control $(\mathrm{n}=38)$ & Dexmedetomidine $(\mathrm{n}=38)$ & $\mathrm{p}$-value \\
\hline Bradycardia & - & $1(2.6 \%)$ & 0.314 \\
\hline Asystole & - & - & - \\
\hline Premature atrial contraction & $21(55.2 \%)$ & $6(15.7 \%)$ & 0.000 \\
\hline Premature ventricular contractions & $31(81.5 \%)$ & $8(21.0 \%)$ & 0.000 \\
\hline Ventricular fibrillation & $4(10.5 \%)$ & $2(5.2 \%)$ & 0.395 \\
\hline Atrial fibrillation & $10(26.3 \%)$ & $3(7.8 \%)$ & 0.033 \\
\hline Atrial flutter & - & - & - \\
\hline Ventricular tachycardia & $8(21.0 \%)$ & $1(2.6 \%)$ & 0.013 \\
\hline First-degree block & - & - & - \\
\hline Second-degree block & $1(2.6 \%)$ & - & 0.314 \\
\hline Third-degree block & - & - & - \\
\hline Cardiac arrest & - & - & - \\
\hline Myocardial infarction & - & - & - \\
\hline ST segment elevation & $6(15.7 \%)$ & $1(2.6 \%)$ & 0.047 \\
\hline ST segment decline & $7(18.4 \%)$ & $1(2.6 \%)$ & 0.025 \\
\hline
\end{tabular}

Table 5. Distribution of pharmaceutical and non-pharmaceutical (antiarrhythmic and hemodynamic controller) actions in patients undergoing off-pump coronary artery bypass surgery between the dexmedetomidine and control groups

\begin{tabular}{|c|c|c|c|c|}
\hline \multicolumn{2}{|l|}{ Variables } & Control $(n=38)$ & Dexmedetomidine $(\mathrm{n}=38)$ & $p$-value \\
\hline \multicolumn{2}{|l|}{ Esmolol, n (\%) } & $4(10.5)$ & - & 0.040 \\
\hline \multicolumn{2}{|l|}{ Labetalol, n (\%) } & - & - & - \\
\hline \multicolumn{2}{|l|}{ Propanol, n (\%) } & - & - & - \\
\hline \multicolumn{2}{|l|}{ Lidocaine, n (\%) } & 9 & 1 & 0.007 \\
\hline \multicolumn{2}{|l|}{ Amiodarone, $\mathrm{n}(\%)$} & - & - & - \\
\hline \multicolumn{2}{|l|}{ Trinitroglycerin (TNG), n (\%) } & $37(97.3)$ & $27(71.0)$ & 0.001 \\
\hline \multicolumn{2}{|l|}{ Dobutamine, $\mathrm{n}(\%)$} & $21(55.2)$ & $8(21.0)$ & 0.002 \\
\hline \multicolumn{2}{|l|}{ Dopamine, $\mathrm{n}(\%)$} & $1(2.6)$ & $1(2.6)$ & 0.999 \\
\hline \multicolumn{2}{|l|}{ Epinephrine, n (\%) } & $10(26.3)$ & $2(5.2)$ & 0.012 \\
\hline \multicolumn{2}{|l|}{ Norepinephrine, n (\%) } & $2(5.2)$ & - & 0.152 \\
\hline \multirow[t]{2}{*}{ Synchronized shock, n (\%) } & Level 1 & $8(21.0)$ & $2(5.2)$ & \multirow[t]{2}{*}{0.095} \\
\hline & Level 2 & $2(5.2)$ & $1(2.6)$ & \\
\hline \multirow[t]{2}{*}{ Unsynchronized shock, $\mathrm{n}(\%)$} & Level 1 & $4(10.5)$ & $2(5.2)$ & \multirow[t]{2}{*}{0.407} \\
\hline & Level 3 & $1(2.6)$ & - & \\
\hline \multicolumn{2}{|l|}{ Use of balloon pump, n (\%) } & $2(5.2)$ & - & 0.152 \\
\hline \multicolumn{2}{|l|}{ Propofol (mg), mean \pm SD } & $1143.4 \pm 336.1$ & $567.1 \pm 142.9$ & 0.000 \\
\hline \multicolumn{2}{|l|}{ Sufentanil, $(\mathrm{mg})$, mean $\pm \mathrm{SD}$} & $232.8 \pm 54.8$ & $120.7 \pm 42.5$ & 0.000 \\
\hline \multicolumn{2}{|l|}{ Midazolam, $(\mathrm{mg})$, mean $\pm \mathrm{SD}$} & $15.6 \pm 2.8$ & $14.4 \pm 1.5$ & 0.029 \\
\hline
\end{tabular}

\section{Discussion}

In the present study, the effect of dexmedetomidine was investigated on the prevention of heart arrhythmias and the results demonstrated that the incidence rate of PAC, PVC, VTAC and AF heart arrhythmias was significantly lower in the intervention group with dexmedetomidine during CABG surgery. Dexmedetomidine is an alpha-2 adrenergic receptor agonist which induces soothing, anti-anxiety and pain effects without reduction in respiratory ventilation (5, 9,12 ), and is increasingly used for patients undergoing cardiac surgery in order for sedation of patients (5). The present study indicated that the use of dexmedetomidine during surgery in more than $90 \%$ of cases prevents the incidence of atrial fibrillation, while one of every three patients in the control group had atrial fibrillation. Liu et al., in a similar study (8), found that the use of dexmedetomidine decreases the AF incidence up to approximately $18 \%$. In the study by Ren (13), the atrial fibrillation cases in the control group were 5 times more than in the dexmedetomidine group. A small retrospective study (14) reported that the patients who received CABG dexmedetomidine were in a lower risk of atrial fibrillation occurrence of new cases compared to similar patients 
who had not received any medication, confirming the results of the present study. On the other hand, the results of the meta-analysis of six studies $(4,13,15-18)$ showed no significant correlations between administration of dexmedetomidine and the incidence level of atrial fibrillation, which does not go along with our results. Possible reasons will be examined further. In the other arrhythmias shown in the present study, the incidence rate of PAC, PVC, VTAC and AF heart arrhythmias was significantly lower in the group treated by dexmedetomidine. Geng et al., in the meta-analysis (1) has shown that the use of dexmedetomidine reduced one-third of the incidence of VTAC among patients undergoing CABG. In addition, other studies $(19,20)$ such as the study of Ren et al. (13) reported a similar effect of dexmedetomidine on the prevention of heart arrhythmias incidence. In the study of Ren et al. (13), the frequency of ventricular tachycardia in the control group was significantly higher than in the dexmedetomidine group. Regarding the effectiveness of dexmedetomidine compared to other analgesics or placebo in reducing the risk of ventricular tachycardia, it seems that dexmedetomidine may be useful for patients with high heart rate, or in the case of some medical procedures leading to tachycardia as endotracheal intubation. However, there are some studies, inconsistent with the results that have not indicated a good efficacy of dexmedetomidine on reducing the incidence rate of other heart arrhythmias, except for atrial fibrillation (19). Potential reasons for the contrary results could be due to the fact that each of the arrhythmia in different studies might have not been evaluated as primary outcome, definition of arrhythmias may not be explicit and identical among the different studies, the patients have been examined at different times to detect postoperative arrhythmias, the type of surgery, the surgeon capabilities, and different kinds of drugs used $(4,16-18)$, as well as the patients with preoperative arrhythmia had not been excluded in many of these studies $(13,16)$. It would be addressed as to how dexmedetomidine can prevent heart arrhythmias; but first, the factors that could potentially be involved in the prevention of postoperative arrhythmia should be noted. Dexmedetomidine can reduce the myocardial ischemia-reperfusion injury and improve the cardiac muscle perfusion in patients after heart surgery $(4,5,9,16-18)$. In addition, the inflammatory response caused by bypass surgery may change the electrophysiology and structure of the atrium layers and lead to increased sensitivity to atrial fibrillation (21). In addition; it is involved in increased hardening of muscles caused by stimulating the development of atrial fibrillation after surgery (21). Dexmedetomidine can reduce catecholamines (22) and prevent arrhythmia-causing effects of epinephrine (23). Moreover, it increases the vagus nerve activity and leads to changes in calcium flow through the membrane of heart muscle cells, which in turn prolongs the duration of repolarization and causes effective refractory period (24). Given the multiple combined effects of organ protection, antiinflammatory features, sympatholytic effects (inhibiting the sympathetic effects) and parasympathomimetic effects (which simulate the effects of parasympathetic), it is not surprising that with the use of dexmedetomidine during the initial period after heart surgery could be effective in preventing the arrhythmia. However, given the proper effectiveness of dexmedetomidine to control some of the arrhythmias especially atrial fibrillation, as a relatively common postoperative problem, it seems that prescription of dexmedetomidine at least would not be useless in controlling the arrhythmia, due to the lack of its irreparable side effects. The occurrence of atrial fibrillation is associated with significant anomalies such as increased risk of heart attacks, mortality after surgery, laparoscopic surgery and a considerable increase in costs of disease treatment $(2,25-27)$.

The most common side effects of dexmedetomidine reported so far are bradycardia and hypotension, which are caused by innate effects of this drug as agonists of alpha-2 receptor $(28,29)$. In the present study, the patients who received dexmedetomidine had lower mean arterial blood pressure and heart rate than the control group at different times, but the interpretation of these findings is valuable if we consider how to control the blood pressure and heart rate in both groups; this is an issue that has not been well studied in other investigations. In our project, various medicinal compounds such as beta-blockers, drugs affecting alpha and beta-adrenergic receptors, inotropic and so on, were used to monitor the hemodynamic status of patients. Based on the findings, the medicinal use of Esmolol, lidocaine, TNG, Dobutamine, propofol, sufentanil and midazolam in the control group was significantly higher compared to the dexmedetomidine group; this means that the hemodynamic changes and the need for anesthetic and analgesic agents due to depth of anesthesia during surgery (to maintain BIS of $=40-60$ ) were lower in the dexmedetomidine group. In addition, specialists have used fewer drug combinations to achieve the hemodynamics and more stable ascents. This finding has not been noted to this detail in other studies and is one of the strengths of our study. However, the lower blood pressure in the dexmedetomidine group was also modified immediately after intravenously injecting the fluids or modifying the speed of vessel constrictor drugs, anesthetics, analgesics, and the need for stopping the study was not required. On the other hand, the results of meta-analysis of seven studies (1) in which dexmedetomidine had been compared with placebo or other analgesics have not shown any differences in the incidence of low blood pressure. However, in the present study, blood pressure and primary heart rate of patients in the dexmedetomidine group were lower than in the control group and the continuing trend of blood pressure reduction cannot be definitively attributed to the use of dexmedetomidine. The results of the present study indicated 
that the use of dexmedetomidine causes more reduction in heart rate, which goes along with the combined results of the five studies $(4,13,15,16,18,19)$. These studies demonstrated that the use of dexmedetomidine increases the risk of bradycardia up to approximately two times. However, the results obtained from these studies, besides the ones of our study, suggest that dexmedetomidine has a definite relationship with bradycardia and possible association with reduction in blood pressure. Therefore, necessary cautions for using this drug should be considered for patients with diseases related to cardiac output, such as patients with low ventricular output fraction (less than $30 \%$ ), heart block and patients at the acute shock phase, because in some cases, stopped sinuses function has been reported during the use of dexmedetomidine $(30,31)$. Previous studies have demonstrated that dexmedetomidine has a biphasic effect on the cardiovascular system. One of the possible reasons for incidence of bradycardia followed by administration of dexmedetomidine, could be the direct activation of postsynaptic $\alpha 2 \mathrm{~B}$-receptors in vascular smooth muscle followed by the initial bolus injection causing vasoconstriction (7). The reason for relationship between dexmedetomidine and high incidence of low blood pressure could be due to the vessel expansion resulting from sympatholysis (inhibition of sympathetic performance) after continuous infusion of intravenous dexmedetomidine (30). It could reduce the sympathetic outflow and activation of presynaptic $\alpha 2$ A-receptors, which in turn, reduces the release of norepinephrine (1).

\section{Limitations}

The patients participating in the study were younger than in those who were used in other studies (mean age of about 60 years compared with almost 65 years) $(32,33)$. Therefore, further studies are needed to investigate the effects of dexmedetomidine in the prevention of heart arrhythmias in elderly patients; mainly due to the higher incidence of heart arrhythmias in this groups of patients. Moreover, in terms of sample size, our study is placed among those with average sample size. Numerous randomized controlled clinical studies have been conducted so far to determine the effects of dexmedetomidine on the prevention of arrhythmias and hemodynamic changes in heart surgery patients, in which 28 subjects (20) have been studied in the smallest research and 306 patients in the largest one (15). It seems that further studies in a larger sample size are needed.

\section{Conclusions}

Based on the results obtained, the use of dexmedetomidine during induction and maintenance of anesthesia can prevent the occurrence of further arrhythmias of PAC, PVC, VTAC and AF. Moreover, the mean arterial blood pressure and heart rate at different studied intervals were lower in the patients administered by dexmedetomidine compared to the control group. Our results also showed that dexmedetomidine significantly reduces the amount of anesthetic compounds. However, due to the absence of consensus among the different studies on the positive effects of dexmedetomidine in the control of some of the most common cardiac arrhythmias including AF, it is recommended that further randomized controlled studies in larger sample sizes and higher quality be performed in order to confirm the effects of dexmedetomidine in cardiac surgery.

\section{Acknowledgments:}

This article has been adapted from research by thesis on Cardiothoracic Anesthesiology Fellowship written by Dr. Shima Sheybani (thesis number: T-4805). This study was fully sponsored by Research Deputy at Mashhad University of Medical Sciences, Iran (grant number 941413).

\section{Conflict of Interest:}

There is no conflict of interest to be declared.

\section{Authors' contributions:}

All authors contributed to this project and article equally. All authors read and approved the final manuscript.

\section{References:}

1) Geng J, Qian J, Cheng H, Ji F, Liu H. The influence of perioperative dexmedetomidine on patients undergoing cardiac surgery: a meta-analysis. PLoS One. 2016; 11(4): e0152829. doi: 10.1371/journal.pone.0152829. PMID: 27049318, PMCID: PMC4822865

2) Mohammad AT, Asghar MA, Asadollah M, Jalal A, Javad S, Alireza SS, et al. The evaluation of right atrial temporary pacing for preventing postoperative atrial fibrillation following coronary artery bypass grafting surgery: prospective observational study. Life Science Journal. 2012; 9(3): 2233-7. 
3) Kabukcu HK, Sahin N, Temel Y, Titiz TA. Hemodynamics in coronary artery bypass surgery: effects of intraoperative dexmedetomidine administration. Der Anaesthesist. 2011 May;60(5):427-31. PubMed PMID: 21271232. Epub 2011/01/29. eng.

4) Karaman Y, Abud B, Tekgul ZT, Cakmak M, Yildiz M, Gonullu M. Effects of dexmedetomidine and propofol on sedation in patients after coronary artery bypass graft surgery in a fast-track recovery room setting. J Anesth. 2015; 29(4): 522-8. doi: 10.1007/s00540-015-1975-2. PMID: 25617159.

5) Ji F, Li Z, Nguyen H, Young N, Shi P, Fleming N, et al. Perioperative dexmedetomidine improves outcomes of cardiac surgery. J Cardiothorac Vasc Anesth. 2014; 28(2): 267-73. doi: 10.1053/j.jvca.2013.06.022. PMID: 24182835, PMCID: PMC4402998.

6) Jalonen J, Hynynen M, Kuitunen A, Heikkila H, Perttila J, Salmenpera M, et al. Dexmedetomidine as an anesthetic adjunct in coronary artery bypass grafting. Anesthesiology. 1997 Feb;86(2):331-45. PubMed PMID: 9054252. Epub 1997/02/01. eng.

7) Ingersoll-Weng E, Manecke GR, Thistlethwaite PA. Dexmedetomidine and cardiac arrest. Anesthesiology. 2004; 100(3): 738-9. doi: 10.1097/00000542-200403000-00040. PMID: 15108994.

8) Liu X, Zhang K, Wang W, Xie G, Fang X. Dexmedetomidine sedation reduces atrial fibrillation after cardiac surgery compared to propofol: a randomized controlled trial. Critical Care. 2016; 20(1): 298. doi: 10.1186/s13054-016-1480-5. PMID: 27654700, PMCID: PMC5031329.

9) Chrysostomou C, Beerman L, Shiderly D, Berry D, Morell VO, Munoz R. Dexmedetomidine: a novel drug for the treatment of atrial and junctional tachyarrhythmias during the perioperative period for congenital cardiac surgery: a preliminary study. Anesth Analg. 2008; 107(5): 1514-22. doi: 10.1213/ane.0b013e318186499c. PMID: 18931208.

10) Chi X, Liao M, Chen X, Zhao Y, Yang L, Luo A, et al. Dexmedetomidine attenuates myocardial injury in off-pump coronary artery bypass graft surgery. Journal of cardiothoracic and vascular anesthesia. 2016;30(1):44-50.

11) Cheng H, Li Z, Young N, Boyd D, Atkins Z, Ji F, et al. The effect of dexmedetomidine on outcomes of cardiac surgery in elderly patients. Journal of cardiothoracic and vascular anesthesia. 2016;30(6):1502-8.

12) Wunsch H, Kahn JM, Kramer AA, Wagener G, Li G, Sladen RN, et al. Dexmedetomidine in the Care of Critically Ill Patients from 2001 to 2007: An Observational Cohort Study. Anesthesiology. 2010; 113(2): 386-94. doi: 10.1097/ALN.0b013e3181e74116. PMID: 20613466.

13) Ren J, Zhang H, Huang L, Liu Y, Liu F, Dong Z. Protective effect of dexmedetomidine in coronary artery bypass grafting surgery. Experimental and therapeutic medicine. 2013; 6(2): 497-502. doi: 10.3892/etm.2013.1183. PMID: 24137215, PMCID: PMC3786847.

14) Narisawa A, Nakane M, Kano T, Momose N, Onodera Y, Akimoto R, et al. Dexmedetomidine sedation during the nighttime reduced the incidence of postoperative atrial fibrillation in cardiovascular surgery patients after tracheal extubation. J Intensive Care. 2015; 3(1): 26. doi: 10.1186/s40560-015-0092-5. PMID: 26060574, PMCID: PMC4460695.

15) Shehabi Y, Grant P, Wolfenden H, Hammond N, Bass F, Campbell M, et al. Prevalence of delirium with dexmedetomidine compared with morphine based therapy after cardiac surgery: a randomized controlled trial (DEXmedetomidine COmpared to Morphine-DEXCOM Study). Anesthesiology. 2009; 111(5): 107584. doi: 10.1097/ALN.0b013e3181b6a783. PMID: 19786862.

16) Park JB, Bang SH, Chee HK, Kim JS, Am Lee S, Shin JK. Efficacy and safety of dexmedetomidine for postoperative delirium in adult cardiac surgery on cardiopulmonary bypass. Korean $\mathrm{J}$ Thorac Cardiovasc Surg. 2014; 47(3): 249-54. doi: 10.5090/kjtcs.2014.47.3.249. PMID: 25207222, PMCID: PMC4157475.

17) Balkanay OO, Goksedef D, Omeroglu SN, Ipek G. The dose-related effects of Dexmedetomidine on renal functions and serum neutrophil gelatinase-associated lipocalin values after coronary artery bypass grafting: a randomized, triple-blind, placebo-controlled study. Interact Cardiovasc Thorac Surg. 2015; 20(2): 209-14. doi: 10.1093/icvts/ivu367. PMID: 25392341.

18) Herr DL, Sum-Ping SJ, England M. ICU sedation after coronary artery bypass graft surgery: dexmedetomidine-based versus propofol-based sedation regimens. J Cardiothorac Vasc Anesth. 2003; 17(5): 576-84. doi: 10.1016/S1053-0770(03)00200-3.

19) Jaionen J, Hynynen M, Kuitunen A, Heikkila H, Perttila J, Salmenpera M, et al. Dexmedetomidine as an anesthetic adjunct in coronary artery bypass grafting. Anesthesiology. 1997; 86(2): 331-45. doi: 10.1097/00000542-199702000-00009. PMID: 9054252.

20) Talke P, Li J, Jain U, Leung J, Drasner K, Hollenberg M, et al. Effects of perioperative dexmedetomidine infusion in patients undergoing vascular surgery. The Study of Perioperative Ischemia Research Group. Anesthesiology. 1995; 82(3): 620-33. doi: 10.1097/00000542-199503000-00003. 
21) Shingu $Y$, Kubota $S$, Wakasa $S$, Ooka $T$, Tachibana $T$, Matsui $Y$. Postoperative atrial fibrillation: mechanism, prevention, and future perspective. Surgery today. 2012; 42(9): 819-24. doi: 10.1007/s00595012-0199-4. PMID: 22619000.

22) Roberts SB, Wozencraft CP, Coyne PJ, Smith TJ. Dexmedetomidine as an adjuvant analgesic for intractable cancer pain. Journal of palliative medicine. 2011;14(3):371-3.

23) Hayashi Y, Sumikawa K, Maze M, Yamatodani A, Kamibayashi T, Kuro M, et al. Dexmedetomidine prevents epinephrine-induced arrhythmias through stimulation of central alpha 2 adrenoceptors in halothane-anesthetized dogs. Anesthesiology. 1991; 75(1): 113-7. doi: 10.1097/00000542-19910700000018. PMID: 1676567.

24) Tobias JD, Chrysostomou C. Dexmedetomidine: antiarrhythmic effects in the pediatric cardiac patient. Pediatric cardiology. 2013; 34(4): 779-85. doi: 10.1007/s00246-013-0659-7. PMID: 23435789.

25) Polanczyk CA, Goldman L, Marcantonio ER, Orav EJ, Lee TH. Supraventricular arrhythmia in patients having noncardiac surgery: clinical correlates and effect on length of stay. Annals of internal medicine. 1998; 129(4): 279-85. doi: 10.7326/0003-4819-129-4-199808150-00003. PMID: 9729180.

26) Amar D, Burt ME, Bains MS, Leung DH. Symptomatic tachydysrhythmias after esophagectomy: incidence and outcome measures. The Annals of thoracic surgery. 1996; 61(5): 1506-9. doi: 10.1016/00034975(96)00111-7.

27) Zirak N, Soltani G, Abbasi M, Hamadanchi A, Moeinipour AA, Javan H, et al. Prophylactic Effect of a Single Intravenous Dose of a Combination of Digoxin, Hydrocortisone, and Amiodarone on Atrial Fibrillation after Off-Pump Coronary Artery Bypasses Graft Surgery. Iranian Heart Journal. 2012; 13(3): 33-8.

28) Kamibayashi T, Maze M. Clinical uses of $\alpha 2$-adrenergic agonists. Anesthesiology. 2000; 93(5): 1345-9. doi: 10.1097/00000542-200011000-00030. PMID: 11046225.

29) Barr J, Fraser GL, Puntillo K, Ely EW, Gélinas C, Dasta JF, et al. Clinical practice guidelines for the management of pain, agitation, and delirium in adult patients in the intensive care unit. Critical care medicine. 2013; 41(1): 263-306. doi: 10.1097/CCM.0b013e3182783b72. PMID: 23269131.

30) Maze M, Scarfini C, Cavaliere F. New agents for sedation in the intensive care unit. Crit Care Clin. 2001; 17(4): 881-97. doi: 10.1016/S0749-0704(05)70185-8. PMID: 11762266.

31) Ingersoll-Weng E, Manecke GR, Thistlethwaite PA. Dexmedetomidine and cardiac arrest. Anesthesiology. 2004; 100(3): 738-9. doi: 10.1097/00000542-200403000-00040. PMID: 15108994.

32) Imazio M, Brucato A, Ferrazzi P, Pullara A, Adler Y, Barosi A, et al. Colchicine for prevention of postpericardiotomy syndrome and postoperative atrial fibrillation: the COPPS-2 randomized clinical trial. JAMA. 2014; 312(10): 1016-23. doi: 10.1001/jama.2014.11026. PMID: 25172965.

33) Halonen J, Halonen P, Järvinen O, Taskinen P, Auvinen T, Tarkka M, et al. Corticosteroids for the prevention of atrial fibrillation after cardiac surgery: a randomized controlled trial. JAMA. 2007; 297(14): 1562-7. doi: 10.1001/jama.297.14.1562. PMID: 17426275. 